\title{
Hubungan Kecerdasan Emosional dengan Akhlak Siswa
}

\author{
Azizah Hilmiyyah ${ }^{1}$, Oking Setia Priatna ${ }^{2}$, Ikhwan Hamdani ${ }^{3}$ \\ Universitas Ibn Khaldun Bogor
}

\begin{abstract}
This study aims to determine the relationship between emotional intelligence and the morals of students in MAN 1 Bogor City. This type of research is quantitative research. The population in this study were students of class XI MAN 1 Bogor City with a total of 353 students. The research sample was taken $15 \%$ of the total number of students in class XI, namely 52.95 rounded to 53 students. Data collection techniques used were observation, questionnaires and documentation, then the data that had been obtained were analyzed by normality test and product moment correlation test. using SPSS 25. The results obtained are based on the sig (2-tailed) value of $0.000<0.05$, which means that there is a significant relationship between emotional intelligence and student morals, besides that, it can be seen from the calculation of the Pearson correlation of 0.743. , and obtained that is 0.743 is in the interval 0.70-0.90, meaning that there is a strong relationship between emotional intelligence and morals.
\end{abstract}

Keywords: Emotional Intelligence, morals, students

\section{PENDAHULUAN}

Akhlak merupakan pembeda antara manusia dengan makhluk lainnya, dengan akhlak seseorang akan dapat berkelakuan baik terhadap Allah SWT, sesama manusia, dan alam. Akhlak bagi manusia menempati kedudukan dan peranan strategis, sehingga hampir semua sendi kehidupan membutuhkan peranan akhlak, akhlak merupakan kebutuhan hidup dalam keluarga, akhlak dapat berperan membentuk kerukunan hidup antar tetangga, akhlak berperan aktif dalam membina pergaulan remaja, akhlak dapat berperan dalam pergaulan umum, akhlak dapat berperan mempertahankan eksistensi suatu negara dan bangsa atau pembangunan, akhlak berperan dalam membina keharmonisan hubungan antar bangsa (Dahlan R, 2014, hal. 102).

Pembentukan akhlak merupakan tujuan penting dalam proses pendidikan, khususnya pendidikan Islam. Akhlak peserta didik dipengaruhi oleh faktor eksternal maupun faktor internal. Faktor eksternal yang mempengaruhi akhlak siswa antara lain keluarga, sekolah dan masyarakat. Sedangkan faktor internal antara lain kecerdasan emosional peserta didik. (Djazimi, 2016).

Berdasarkan uraian di atas, Peneliti sangat tertarik untuk melakukan penelitian lebih lanjut dengan mengangkat judul Hubungan Kecerdasan Emosional Dengan Akhlak Siswa Di Man 1 Kota Bogor. Adapun tujuan penelitian ini adalah untuk mengetahui apakah terdapat hubungan antara kecerdasan emosional dengan akhlak siswa di MAN 1 Kota Bogor 


\section{METODE PENELITIAN}

Penelitian ini menggunakan pendekatan kuantitatif. Adapun metode yang digunakan adalah korelasional, yaitu ditujukan untuk mengetahui hubungan suatu variabel dengan variabel lainnya. Sementara itu bentuk-bentuk yang digunakan dalam mengumpulkan data dalam penelitian adalah sebagai berikut: wawancara (interview) yang terdiri dari wawancara terstruktur dan wawancara tidak terstruktur, angket (Quesioner), dan observasi.

\section{KAJIAN TEORI}

\section{A. Kecerdasan Emosional}

Kecerdasan ialah istilah umum yang digunakan untuk menjelaskan sifat fikiran yang mencakup sejumlah kemampuan, seperti kemampuan menalar, merencanakan masalah, berfikir abstrak, memahami gagasan, menggunakan Bahasa dan belajar.

Menurut (Muhammad Idris Jauhari dalam buku Pengantar Ilmu Jiwa Umum Dengan Konfirmasi Islam: 2015, 67) yang dimaksud kecerdasan adaalah kemampuan mempergunakan fungsi pikiran dengan cepat dan tepat untuk mengatasi situasi atau memecahkan masalah. Sejalan dengan ittu, Howard Gardner mendefinisikan kecerdasan adalah kemampuan untuk memecahkan suatu masalah. Setiap manusia pasti memiliki masalah, baik itu masalah yang timbul dari luar maupun dari dalam diri. Kecerdasan berperan penting bagi manusia dalam mengolah dirinya untuk memecahkan masalah yang timbul dalam diri. (Much, 2018) Adapun faktor-faktor yang mempengaruhi kecerdasan menurut Daryanto ada lima, yaitu pembawaan, kematangan, pembentukan, minat dan pembawaan yang khas dan terakhir adalah kebebasan. (Deni \& Muhammad Rizki, 2020)

Bagian ini memuat landasan teori berupa rangkuman teori-teori dari pustaka yang mendukung penelitian, serta memuat penjelasan tentang konsep dan prinsip dasar yang diperlukan untuk pemecahan permasalahan. Landasan teori berbentuk uraian kualitatif, model matematis, atau tools yang langsung berkaitan dengan permasalahan yang diteliti.

Emosi adalah suatu rahmat yang diberikan Allah SWT sejak roh ditiupkan pada rahim ibu, untuk itu sangat diperlukan kecerdasan emosi. Kecerdasan emosi ini sangat penting terhadap pengendalian diri seseorang maupun terhadap orang lain, khususnya untuk mereduksi ketegangan yang timbul akibat konflik batin yang memuncak. Dalam konteks ini, Al-Qur'an memberi petunjuk pada manusia agar mengendalikan emosinya guna mengurangi ketegangan-ketegangan fisik dan psikis serta efek negatif yang ditimbulkannya. Begitu pula dalam hadits Nabi SAW banyak yang mengingatkan pengikutnya untuk selalu mengontrol emosi agar terciptanya kehidupan yang selaras dan seimbang dan mencapai kehidupan Bahagia dunia dan akhirat. (R.Rachmy, 2015)

Menurut Salovey dan Mayer, Emotional Intelligence (EQ) adalah kemampuan mengenali, mengelola, mengekspresikan emosi, dan memotivasi diri sendiri, mengenali orang lain, dan membina hubungan dengan orang lain dengan tepat. (Nyanyu, 2014). Sementara itu menurut para pakar mendefinisikan Emotional Intelligence (EQ) adalah 
kemampuan dalam bentuk menerima, memahami, dan mengelola untuk menyikapi pengetahuan-pengetahuan emosional (DR. Makmun, 2010, p. 7). Sejalan dengan itu, Robert dan Cooper mengungkapkan bahwa Emotional Intelligence (EQ) adalah kemampuan merasakan, memahami secara efektif dalam menerapkan daya dan kepekaan emosi sebagai sumber energi, koneksi dan pengaruh yang manusiawi. Individu yang mampu memahami emosi individu lain, dapat bersikap dan mengambil keputusan dengan tepat tanpa menimbulkan dampak yang merugikan kedua belah pihak.

\section{B. Akhlak}

Akhlak merupakan bagin dari perintah Allah SWT. dan inti dari syari'at Islam. Secara Bahasa, akhlak berasal dari kata al-khuluq yang berarti kebiasaan (as-sajiyah) dan tabi'at (at-tab'u). Sedangkan secara istilah, akhlak adalah sifat-sifat yang diperintahkan oleh Allah SWT. kepada seorang muslim untuk dimiliki tatkala ia melaksanakan aktivitasnya. (Muhammad Husain, 2012, p. 123)

Ibn Miskawaih yang dikenal sebagai pakar bidang akhlak terkemuka dan terdahulu mengatakan, bahwa akhlak adalah:

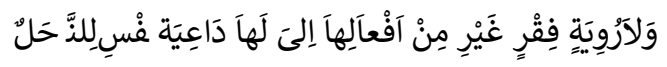

"Sifat yang tertanam dalam jiwa yang mendorong seseorang untuk melakukan segala perbuatan tanpa harus difikirkan dan dipertimbangkan."

Sementara itu, Imam Al-Ghazali yang dikenal sebagai Hujjatul Islam mengatakan lebih luas, bahwa akhlak adalah:

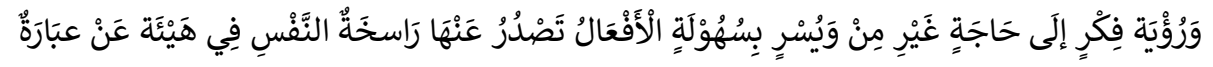

"ungkapan yang menggambarkan kondisi jiwa dan menimbulkan macam-macam perbuatan dengan penuh kemudahan tanpa memerlukan proses pemikiran dan pertimbangan."

Sejalan dengan itu, dalam Mu'jam al-Wasith, Ibrahim Anis mengatakan bahwa, akhlak adalah:

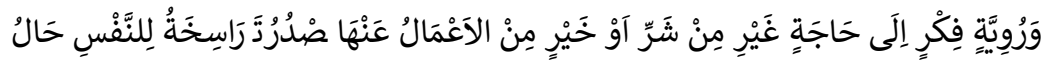

"keadaan jiwa, yang melahirkan macam-macam perbuatan baik atau buruk, tanpa membutuhkan pemikiran dan peertimbangan." (Abudin, 2017: 3)

Senada dengan itu, al-Jurjani melalui kitab Kitāb Ta'rīfătnya mendefinisikan akhlak sebagaimana berikut:

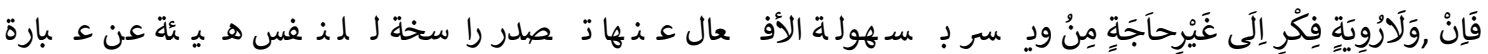

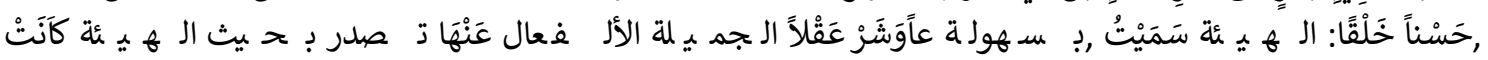

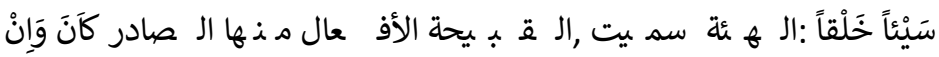

“akhlak adalah keadaan jiwa yang melekat dan keluar darinya segala perbuatan dengan mudah tanpa memerlukan pemikiran dan pertimbangan. Apabila menurut akal dan syari' at keadaan jiwa tersebut melahirkan perbuatan-perbuatan baik, maka disebut dengan akhlak hasanah, namun apabila keluar darinya perbuatan-perbuatan buruk maka disebut akhlak tercela." (Syafa'atul, 2017: 54-55) 
Dari beberapa pendapat para ahli diatas, dapat disimpulkan bahwa akhlak adalah sifat seseorang yang melahirkan perbuatan baik atau buruk sehingga menjadi sebuah kepribadian yang melekat pada jiwa yang dilakukan dengan mudah tanpa pemikiran dan pertimbangan.

\section{HASIL PENELITIAN DAN PEMBAHASAN}

\section{Hasil Penelitian}

Dalam penelitian ini peneliti menggunakan data yang diperoleh dari hasil penyebaran kuesioner, yaitu dengan cara menyebarkan secara online melalui google form kepada siswa-siswi MAN 1 Kota Bogor, agar menghasilkan data yang relevan dengan jumlah sampel 53 orang dari dua kelas yaitu XI agama XI IPS, Adapun data yang diperoleh dari hasil pengisian kuesioner yang dilakukan pada siswa-siswi MAN 1 Kota Bogor terdapat pada lampiran. Presentase dari masing-masing jawaban item angket diselesaikan melalui tabel, pentabulasian seluruh hasil angket.

Tabel 4.1

Rekapitulasi Variabel X

\begin{tabular}{|c|c|c|c|c|c|c|c|c|c|c|}
\hline \multirow{4}{*}{$\begin{array}{c}\text { No. } \\
\text { Pernayataan }\end{array}$} & \multicolumn{10}{|c|}{ Angket Variabel X } \\
\hline & \multicolumn{8}{|c|}{ Skor Jawaban } & \multirow{2}{*}{\multicolumn{2}{|c|}{ Jumlah }} \\
\hline & \multicolumn{2}{|c|}{4} & \multicolumn{2}{|c|}{3} & \multicolumn{2}{|c|}{2} & \multicolumn{2}{|c|}{1} & & \\
\hline & $\mathrm{F}$ & $\%$ & $\mathrm{~F}$ & $\%$ & $\mathrm{~F}$ & $\%$ & $\mathrm{~F}$ & $\%$ & $\mathrm{~F}$ & $\%$ \\
\hline 1 & 27 & 14 & 14 & 26,4 & 11 & 20,8 & 1 & 1,9 & 53 & 100 \\
\hline 2 & 31 & 58,5 & 10 & 18,9 & 10 & 18,9 & 2 & 3,7 & 53 & 100 \\
\hline 3 & 0 & 0 & 6 & 11,3 & 29 & 54,7 & 18 & 34 & 53 & 100 \\
\hline 4 & 9 & 17 & 20 & 37,7 & 22 & 41,5 & 2 & 3,8 & 53 & 100 \\
\hline 5 & 12 & 22,6 & 18 & 34 & 23 & 43,4 & 0 & 0 & 53 & 100 \\
\hline 6 & 12 & 22,6 & 14 & 26,4 & 21 & 39,6 & 6 & 11,4 & 53 & 100 \\
\hline 7 & 29 & 54,7 & 15 & 28,3 & 8 & 15,1 & 1 & 1,9 & 53 & 100 \\
\hline 8 & 11 & 20,8 & 14 & 26,4 & 27 & 50,9 & 1 & 1,9 & 53 & 100 \\
\hline 9 & 5 & 9,4 & 9 & 17 & 27 & 51 & 12 & 22,6 & 53 & 100 \\
\hline 10 & 1 & 1,9 & 2 & 3,8 & 23 & 43,4 & 27 & 50,9 & 53 & 100 \\
\hline 11 & 21 & 39,6 & 23 & 43,4 & 9 & 17 & 0 & 0 & 53 & 100 \\
\hline
\end{tabular}




\begin{tabular}{|c|c|c|c|c|c|c|c|c|c|c|}
\hline 12 & 23 & 43,4 & 16 & 28,3 & 12 & 24,5 & 2 & 3,8 & 53 & 100 \\
\hline 13 & 13 & 24,5 & 12 & 22,6 & 24 & 45,3 & 4 & 7,6 & 53 & 100 \\
\hline 14 & 34 & 64,2 & 9 & 17 & 7 & 13,2 & 3 & 5,6 & 53 & 100 \\
\hline 15 & 8 & 18,9 & 20 & 30,2 & 16 & 37,7 & 9 & 13,2 & 53 & 100 \\
\hline Jumlah & 236 & 389,5 & 202 & 317 & 269 & 517 & 88 & 162,3 & & \\
\hline Rata-Rata & 15,73 & 25,97 & 13,47 & 21,13 & 17,93 & 34,47 & 5,87 & 10,8 & & \\
\hline
\end{tabular}

Berdasarkan tabel di atas, dapat disimpulkan rekapitulasi siswa MAN 1 Kota Bogor, rata-rata persentase variabel $\mathrm{X}$ : alternatif jawaban selalu memiliki rata-rata $25,97 \%$, alternatif jawaban sering memiliki rata-rata $21,13 \%$, alternatif jawaban kadangkadang memiliki rata-rata $34,47 \%$, alternatif jawaban tidak pernah memiliki rata-rata $10,8 \%$.

Dengan demikian dapat diketahui bahwa jumlah terbanyak pada variabel $\mathrm{X}$ adalah alternatif jawaban kadang-kadang dengan skor 2 yang rata-ratanya 34,47\%, sehingga dapat diketahui bahwa mayoritas siswa menjawab kadang-kadang.

Tabel 4.2.

Rekapitulasi Variabel Y

\begin{tabular}{|c|c|c|c|c|c|c|c|c|c|c|}
\hline \multirow{4}{*}{$\begin{array}{c}\text { No. } \\
\text { Pernayataan }\end{array}$} & \multicolumn{10}{|c|}{ Angket Variabel Y } \\
\hline & \multicolumn{8}{|c|}{ Skor Jawaban } & \multirow{2}{*}{\multicolumn{2}{|c|}{ Jumlah }} \\
\hline & \multicolumn{2}{|r|}{4} & \multicolumn{2}{|c|}{3} & \multicolumn{2}{|c|}{2} & \multicolumn{2}{|c|}{1} & & \\
\hline & $\mathrm{F}$ & $\%$ & $\mathrm{~F}$ & $\%$ & $\mathrm{~F}$ & $\%$ & $\mathrm{~F}$ & $\%$ & $\mathrm{~F}$ & $\%$ \\
\hline 1 & 4 & 7,5 & 7 & 13,2 & 25 & 47,2 & 17 & 32,1 & 53 & 100 \\
\hline 2 & 20 & 37,7 & 21 & 39,6 & 11 & 20,8 & 1 & 1,9 & 53 & 100 \\
\hline 3 & 43 & 81,7 & 9 & 17 & 1 & 1,9 & 0 & 0 & 53 & 100 \\
\hline 4 & 42 & 49,2 & 9 & 19 & 2 & 3,8 & 0 & 0 & 53 & 100 \\
\hline 5 & 41 & 77,4 & 8 & 15,1 & 4 & 7,5 & 0 & 0 & 53 & 100 \\
\hline 6 & 32 & 60,4 & 12 & 22,6 & 9 & 17 & 0 & 0 & 53 & 100 \\
\hline 7 & 2 & 3,8 & 7 & 13,2 & 38 & 71,7 & 6 & 11,3 & 53 & 100 \\
\hline
\end{tabular}




\begin{tabular}{|c|c|c|c|c|c|c|c|c|c|c|}
\hline 8 & 21 & 39,6 & 15 & 28,3 & 17 & 32,1 & 0 & 0 & 53 & 100 \\
\hline 9 & 43 & 81,1 & 7 & 13,2 & 3 & 5,7 & 0 & 0 & 53 & 100 \\
\hline 10 & 37 & 69,8 & 12 & 22,6 & 4 & 7,5 & 0 & 0 & 53 & 100 \\
\hline 11 & 35 & 66 & 10 & 18,9 & 8 & 15,1 & 0 & 0 & 53 & 100 \\
\hline 12 & 0 & 0 & 0 & 0 & 25 & 47,2 & 28 & 52,8 & 53 & 100 \\
\hline 13 & 1 & 1,9 & 0 & 0 & 16 & 30,2 & 36 & 67,9 & 53 & 100 \\
\hline 14 & 10 & 18,9 & 24 & 45,3 & 14 & 26,4 & 5 & 9,4 & 53 & 100 \\
\hline 15 & 38 & 71,1 & 12 & 22,6 & 3 & 5,7 & 0 & 0 & 53 & 100 \\
\hline 16 & 0 & 0 & 0 & 0 & 6 & 11,3 & 47 & 88,7 & 53 & 100 \\
\hline 17 & 35 & 66 & 12 & 22,6 & 6 & 11,3 & 0 & 0 & 53 & 100 \\
\hline 18 & 6 & 11,3 & 14 & 26,4 & 30 & 56,6 & 3 & 5,7 & 53 & 100 \\
\hline 19 & 31 & 58,5 & 15 & 28,3 & 7 & 13,2 & 0 & 0 & 53 & 100 \\
\hline 20 & 13 & 24,5 & 13 & 24,5 & 22 & 41,5 & 5 & 9,4 & 53 & 100 \\
\hline Jumlah & 454 & 826,4 & 207 & 392,4 & 251 & 473,7 & 148 & 279,2 & & \\
\hline Rata-Rata & 22,7 & 41,32 & 10,35 & 19,62 & 12,55 & 21,85 & 7,4 & 13,95 & & \\
\hline
\end{tabular}

Sedangkan berdasarkan kapitulasi variabel $\mathrm{Y}$ memiliki rata-rata persentase: alternatif jawaban selalu memiliki rata-rata $41,32 \%$, alternatif jawaban sering memiliki rata-rata $19,62 \%$, alternatif jawaban kadang-kadang memiliki rata-rata $21,85 \%$, alternatif jawaban tidak pernah memiliki rata-rata $13,95 \%$.

Dengan demikian dapat diketahui jumlah terbanyak pada variabel $\mathrm{Y}$ adalah alternatif jawaban dengan skor 4 yang rata-ratanya 41,32\%, sehingga dapat dketahui bahwa mayoritas siswa menjawab selalu.

Uji korelasi bertujuan untuk mengetahui tingkat keeratan hubungan antar variabel yang dinyatakan dengan koefisien korelasi (r). Dasar pengambilan keputusan:

Jika nilai signifikansi $<0,05$, maka berkorelasi

Jika nilai signifikansi $>0,05$, maka tidak berkorelasi,

Kemudian dari hasil penelitian di atas, dicari tingkat korelasi Variabel $\mathrm{X}$ (Kecerdasan Emosional) terhadap Variabel Y (Akhlak Siswa) dengan menggunakan tabel interpretasi sebagai berikut: 
Interpretasi Nilai

\begin{tabular}{|c|c|}
\hline $\begin{array}{c}\text { Besarnya "r" } \\
\text { Product Moment }\end{array}$ & Interpretasi \\
\hline $0,00-0,20$ & $\begin{array}{c}\text { Antara variabel X dan Y memang terdapat korelasi, akan } \\
\text { tetapi korelasi itu sangat lemah atau sangat rendah. } \\
\text { Antara variabel X dan Y terdapat korelasi yang lemah } \\
\text { atau rendah. }\end{array}$ \\
\hline $0,20-0,40$ & Antara variabel X dan Y terdapat korelasi yang sedang. \\
\hline $0,40-0,70$ & $\begin{array}{c}\text { Antara variabel X dan Y terdapat korelasi yang baik atau } \\
\text { kuat. }\end{array}$ \\
\hline $0,70-0,90$ & Antara variabel X dan Y terdapat korelasi yang sangat \\
baik atau sangat kuat.
\end{tabular}

Setelah dilakukan uji korelasi dengan rumus korelasi pearson dengan taraf signifikan 5\%, maka didapatkan hasil penelitian sebagai berikut:

Tabel 4.4

\begin{tabular}{|c|c|c|c|}
\hline \multicolumn{4}{|c|}{ Correlations } \\
\hline & & $\begin{array}{l}\text { Kecerdasan } \\
\text { Emosional }\end{array}$ & Akhlak Siswa \\
\hline \multirow[t]{3}{*}{ Kecerdasan Emosional } & Pearson Correlation & 1 & $.743^{* *}$ \\
\hline & Sig. (2-tailed) & & .000 \\
\hline & $\mathrm{N}$ & 53 & 53 \\
\hline \multirow[t]{3}{*}{ Akhlak Siswa } & Pearson Correlation & $.743^{* *}$ & 1 \\
\hline & Sig. (2-tailed) & .000 & \\
\hline & $\mathrm{N}$ & 53 & 53 \\
\hline
\end{tabular}

Setelah dilakukan uji korelasi dengan bantuan spss versi 25 maka diketahui bahwa terdapat hubungan antara keceersadan emosional dengan akhlak siswa. Hal ini dilihat berdasarkan nilai sig(2-tailed) yakni sebesar 0,000 < 0,05, sehingga Ha diterima dan Ho ditolak. Selain itu, berdasarkan tabel diatas menunjukkan adanya korelasi variabel $\mathrm{X}$ dan Y sebesar 0,743, dapat dilihat dari tabel interpretasi nilai yang diperoleh yaitu 0,743 berada pada interval 0,70-0,90 artinya korelasi antara kecerdasan emosional dengan akhlak bersifat kuat. 


\section{Pembahasan}

Penelitian ini dilakukan di MAN 1 Kota Bogor dengan jumlah responden 53 siswa dan instrumen dalam penelitian ini menggunakan kuesioner dengan jumlah pernyataan 35 butir untuk variabel $\mathrm{X}$ dan $\mathrm{Y}$, kemudian dilakukan uji validitas menggunakan alat bantu SPSS versi 25 dan hasil uji validalitas tersebut dari 35 butir pernyataan terdapat 30 butir soal questioner yang valid, dan 5 butir soal tidak valid atau gugur, selanjutnya dilakukan uji reliabilitas, maka didapat hasil variabel $\mathrm{x}$ sebesar 0,668 dan variabel $\mathrm{Y}$ sebesar 0,830. Hal ini berarti instrument yang digunakan dalam penelitian itu reliabel. selanjutnya dilakukan uji normalitas dan didapatlah hasil nilai signifikan 0,200, Sehingga dapat disimpulkan bahwa data yang digunakan berdistribusi normal, karena 0,200 >0,05.

Berdasarkan data dari hasil penelitian yang telah diuraikan diatas, bahwa terdapat hubungan antara kecerdasan emosional dengan akhlak siswa. Hal ini dapat dilihat dari hasil kuesioner masing-masing variabel. Setelah dilakukan uji korelasi dengan taraf signifikan 5\% maka nilai korelasi sebesar 0,743 yang terletak antara interval 0,70-0,90 ini artinya terdapat hubungan yang bersifat kuat. sehingga peneliti dapat memperoleh kesimpulan bahwa hubungan kecerdasan emosional dengan akhlak siswa berada pada tingkat hubungan yang kuat.

Berdasarkan hasil di atas, maka (Ho) ditolak, dan hal ini berarti (Ha) diterima, atau dengan kata lain terdapat hubungan antara kecerdasan emosional dengan akhlak siswa. Hasil analisis tersebut dapat disimpulkan bahwa semakin tinggi kecerdasan emosional maka semakin tinggi akhlak siswa yang ditunjukkan. Sebaliknya, semakin rendah kecerdasan emosional maka akhlak siswa semakin rendah.

\section{SIMPULAN}

Berdasarkan data yang diperoleh dalam penelitian dan analisa data melalui perhitungan skor angket dapat disimpulkan bahwa terdapat hubungan antara keceerdasan emosional dengan akhlak siswa di MAN 1 Kota Bogor. Hal ini dapat dilihat melalui nilai $\operatorname{sig}(2$-tailed) $0,000<0,05$. Ini menunjukkan bahwa Ha diterima dan Ho ditolak. Adapun hubungan anatara kecerdasan emosional dengan akhlak siswa bersifat kuat berdasarkan tabel interpretasi sebesar 0,743 berada pada interval 0,70-0,90.

Adapun saran yang dapat peneliti sampaikan untuk siswa-siswi adalah agar dapat lebih melatih kecerdasan emosional agar dapat membentuk akhlak siswa yang baik, karena kecerdasan emosional dapat mempengaruhi akhlak siswa dalam kehidupan seharihari. Sementara bagi Pendidik di Sekolah sebagai sebuah Lembaga Pendidikan formal diharapkan selalu mendukung dan membimbing siswa-siswi dalam melatih kecerdasan emosional agar akhlak siswa dapat terbentuk dengan baik. Kemudian disarankan pula bagi Peneliti Selanjutnya yang tertarik untuk melakukan penelitian dengan tema kecerdasan emosional diharapkan dapat mempertimbangkan variabel-variabel lain yang mempengaruhi akhlak siswa untuk memberikan pengetahuan baru selain faktor kecerdasan emosional. 


\section{DAFTAR PUSTAKA}

D. M. (2010). Kecerdasan\&Kesehatan Emosional Anak. Jakarta: Pustaka Al-Kautsar

Dahlan R, M. (2014). Studi Islam. Bogor: Pustaka Al-Bustan

Djazimi, M. (2016). Pengaruh kecerdasan emosional terhadap akhlak siswa madrasahaliyah al-khairiyah provinsi banten. Jurnal Ilmiah Pendidikan

Gusniwati, M. (2015). Pengaruh kecerdasan emosional dan minat belajar terhadap penguasaan konsep matematika siswa. Jurnal Formatif

M. A., \& M. A. (2016). psikologi remaja. Jakarta: PT.Bumi Aksara

M. S. (2018). Peran guru pai dalam mengembangkan kecerdasan emosional (eq) dan kecerdasan spiritual (sq) siswa smk komputama majenang . jurnal tawadhu Vol. 1 no. 3

Mutmainah. (2017). Hubungan emotional intelligence dengan akhlak siswa

A. N. (2017). Akhlak Tasawuf dan Karakter Mulia. Jakarta: PT RajaGrafindo Persada

D. I., \& M. F. (2020). Konsep pemahaman agama islam terhadap emosional anak. jurnal dirasat islamiyah Vol.7 no.2

E. 1. (2017). Psikologi Dasar. Bandung: PT. Remajaa Rosdakarya.

F. H. (2012). Buku Teks Pendidikan Agama Islam Pada Perguruan Tinggi Umum. Bogor: IPB Press.

H. S., \& I. S. (2012). Akhlak Tasawuf. Jakarta: Kalam Mulia.

I. R. (2015). Integrasi nilai-nilai kecerdasan emosional dalam kurikulum pendidikan agama islam di sma: perspektif daniel goleman . Jurnal Studia Islamika Vol.12 no.1

M. R. (2016). Konsep Pembelajaran Aqidah Akhlak. Yogyakarta: Deepublish

M. R. (2017). Membangun Spiritualitas \& Kemuliaan Sikap. Yogyakarta: Samudra Biru

M. S. (2018). Peran guru pai dalam mengembangkan kecerdasan emosional (eq) dan kecerdasan spiritual (sq) siswa smk komputama majenang. Jurnal Tawadhu Vol.1 no.3

Mahjuddin. (2010). Akhlak Tasawuf II. Jakarta: Kalam Mulia

N. K. (2014). Psikologi Pendidikan. Jakarta: PT RajaGrafindo Persada

R. A. (2016). Pengantar Pendidikan Asas\&Filsafat Pendidikan. Yogyakarta: Ar-Ruzz Media

S. A. (2015). Hubungan Kecerdasan Emosi dengan Penyesuaian Diri Siswa di Sekolah. Jurnal KOPASTA Vol.2 No.2 
S. H. (2017). Kecerdasan Emosional dalam Al-Qur'an. Jurnal Of Psychological Research Vol.3 no. 1

S. H. (2018). Akidah Akhlak Etika Islam. Banda Aceh: Bina Karya Akademika

S. J. (2017). Konsep Akhlak menurut Ibn Miskawaih. Taasfiyah Jurnal Pemikiran Islam Vol.1 no. 1

H., \& E. B. (2014). Metode Penelitian Kuantitatif Aplikasi dalam Pendidikan. Yogyakarta: Deepublish

A. H., \& E. B. (2014). Metode Penelitian Kuantitatif Aplikasi dalam Pendidikan. Yogyakarta: Deepublish

A. M. (2017). Metode Penelitian Kuantitatif, Kualitatif dan Penelitian Gaabungan. Jakarta: Kencana

D. M. (2010). Kecerdasan\&Kesehatan Emosional Anak. Jakarta: Pustaka Al-Kautsar

H. D. (2014). Metode Penelitian Pendidikan dan Sosial. Bandung: Alfabeta

Jakni. (2016). Metodologi Penlitian Eksperimen Bidang Pendidikan . Bandung: Alfabeta

M. A. (2012). Studi Dasar-Dasar Pemikiran Islam. Bogor: Pustaka Thariqul Izzah

M. R., \& N. A. (2017). Hubungan Antara Taayangan Ibu Pintar Dengan Sikap Orang Tua Dalam Mendidik Anak. Jurnal Politikom Indonesia, Vol.2 No.2

Mahjuddin. (2010). Akhlak Tasawuf II. Jakarta: Kalam Mulia

Muhyani. (2019). Metode Penelitian. Bogor: UIKA Press

N. K. (2014). Psikologi Pendidikan. Jakarta: PT Rajagrafindo Persada 